\title{
MAKNA SIMBOL MOTIF SONGKET PADA SITUS KOMPLEKS MAKAM KAWAH TENGKUREP
}

\author{
Widia Ningsih ${ }^{1}$, Masyhur ${ }^{2}$, Padila $^{3}$ \\ ${ }^{123}$ Prodi Sejarah Peradaban Islam Fakultas Adab dan Humaniora \\ Universitas Islam Negeri Raden Fatah Palembang \\ Gmail: widia9458@gmail.com
}

\begin{abstract}
Abstrak
Kawah tengkurep merupakan tempat pemakaman kesultanan Palembang yang dibangun pada 1728 yang terdiri dari empat cungkup. Penelitian ini difokuskan pada makna simbol motif sognket pada situs kompleks makam kawah tengkurep dapat memberikan informasi mengenai perkembangan kebudayaan seni pada masa kesultanan Palembang. Berdasarkan hasil penelitian terdapat empat motif songket beserta makna simbolnya yang ditemukan di Kompleks Makam Kawah Tengkurep yaitu motif tumpal, motif meru, motif geometris dan motif berante. Metode yang digunakan untuk menjawab permasalahan tersebut adalah melalui observasi dan studi pustaka. Data yang sudah terkumpul kemudian dianalisis dan diambil kesimpulan.
\end{abstract}

Kata Kunci: makna simbol, songket, makam

\begin{abstract}
Tengkurep Crater is the burial place of the Palembang Sultanate which was built in 1728 which consists of four cupolas. This research is focused on the meaning of the symbol of the Sognket motif on the site of the Tengkurep Crater tomb complex which can provide information about the development of artistic culture during the Palembang Sultanate. Based on the results of the study, there were four songket motifs and their symbolic meanings found at the Tengkurep Crater Tomb Complex, namely the tumpal motif, the meru motif, the geometric motif and the berante motif. The method used to answer these problems is through observation and literature study. The data that has been collected is then analyzed and conclusions are drawn.
\end{abstract}

Keywords: meaning of symbols, songket, tomb

\section{A. PENDAHULUAN}

Songket ada sejak masa Kerajaan Palembang yaitu sekitar tahun 1629, pada waktu itu songket merupakan pakaian bangsawan yang disesuaikan dengan kedudukannya. Pada masa kesultanan abad ke-16-17 kain dengan tenunan benang emas dan benang perak sangat populer dikalangan masyarakat. Kegemaran pemakaian songket oleh para raja Palembang dan kerabat keratin terus berlanjut pada masa Kesultanan Palembang sejak 1666-1823. ${ }^{1}$

Songket Palembang mempunyai motif-motif tersendiri untuk mempercantik kerajinan. Motif sendiri adalah ragam hias yang dipergunakan untuk memperindah dan mempercantik hasil kerajinan statis, dari dahulu sampai sekarang tidak ada perubahan. Jenis ragam hias antara lain Falora, fauna, pilin berganda, geometris, dan tumpal. ${ }^{2}$

Motif-motif yang terdapat pada makam di langsungkan pada motif yang ada di songket. Salah satu makam yang banyak ditemukan di Sumatera Selatan yaitu makam yang ada kompleks makam kawah tengkurep. Ragam hias yang ditemukan di kompleks makam kawah tengkurep telah

\footnotetext{
${ }^{1}$ Retno Purwanti dan Sondang M. Siregar, "Sejarah Songket Berdasarkan Data Arkeologi,” Siddhayatra (2016): hlm.98.

${ }^{2}$ Dekdikbud, Esiklopedia Nasional Indonesia Jilid VIII, Jakarta: PT Cipta Abadi Pustaka, 1992, hlm. 351-352.
} 
membuktikan bentuk kebudayaan seni pada masa kesultanan Palembang yang memiliki kerajinan seni tenun yaitu songket. Motif songket ini banyak digunakan di pemakaman kesultanan Palembang.

Di dalalam kompleks makam Kawah Tengkurep Palembang terdapat beberapa makam Sultan Palembang Darussalam berserta para zuriatnya. Makam ini terdiri dari empat cungkup yaitu kompleks makam Sultan Badaruddin 1, kompleks makam Pangeran Kamuk, Kompleks Makam Ahmad Najamuddin, dan kompleks makam Bahauddin. Lokasi makam kawah tengkurep Palembang terletak di jalan lemabang 3 Ilir Palembang. ${ }^{3}$

\section{B. TINJAUAN PUSTAKA}

Dalam penelitian ini penulis menemukan beberapa penelitian yang berkaitan dengan makam kawah tengkurep, hanya saja tidak ada yang spesifik membahas tentang penerusan motif pada songket. Beberapa penelitian tersebut diantaranya adalah Skripsi yang berjudul ornamen bangunan cungkup pada kompleks Makam Kawah Tengkurep oleh Arip Muhtiar, Program Studi Sejarah Peradaban Islam, Fakulutas Adab dan Humaniora UIN Raden Fatah Palembang. Skripsi ini membahas tentang deskripsi bentuk fisik bangunan dan ornamen pada cungkup I di makam kawah tengkurep.

Selain itu ada juga skripsi yang berjudul. Ragam Hias Dan Makna Simbol Pada Nisan Kompleks Makam Kawah Tengkurep Di Palembang (Kajian Arkeologis Dan Historis) oleh Siti Aminah (2018), penelitian ini memaparkan tentang ragam hias dan makna simbol pada Nisan Kompleks Makam Kawah Tengkurep di Kelurahan 3 Ilir, Kecamatan Ilir Timur II, Kota Palembang.

Jurnal Siddhayatra yang berjudul Sejarah Songket Berdasarkan Data Arkeologi oleh Retno Purwanti dan Sodang M. Siregar. Penelitian ini membahas tentang sejarah songket di Palembang berdasarkan data arkeologi.

Dari beberapa penelitian yang telah dipaparkan diatas, peneliti ingin memperkaya kajian tentang ragam hias situs makam Kawah Tengkurep: kelangsungan terhadap motif songket yang belum ada penelitian mengenai hal itu, sehingga penelitian ini penting dilakukan guna memberikan informasi mengenai motif-motif di makam Kawah Tengkurep dalam kelangsunganya di motif songket.

\section{METODE PENELITIAN}

Metode dalam penelitian ini terdiri dari beberapa tahapan penelitian yaitu pengumpulan data atau observasi, pengolahan dan penafsiran data. Tahap observasi atau mengumpulkan data hasil survei tahap pengolahan data adalah tahap menggabungkan data dan menempatkanya ke dalam tempattempat klasifikasi yang sesuai dengan integration, dan penafsiran data yang merupakan penarikan kesimpulan dari data yang telah di analisis pada tahap sebelumnya.

Dalam tahapan observasi atau pengumpulan data, kegiatan yang dilakukan adalah mengumpulkan data primer dan sekunder. Data primer dalam penelitian ini adalah ragam hias di situs makam kawah tengkurep yang motifnya erdapat juga disongket. Dari hasil pengamatan, ditemukan 4 ragam hias makam yang sama dengan motif songket. Selanjutnya tahap pendeskripsian, tahap ini yang harus diperhatikan adalah bentuk hiasan. Bentuk hiasan yang terdapat pada setiap motif ragam hias makam serta pengambilan foto. Pengumpulan data sekunder melalui data kepustakaan untuk merekontruksi songket.

Tahapan terakhir dalam penelitian ini adalah penarikan kesimpulan dari data yang telah diolah pada tahap sebelumnya. Analisis pada tahap sebelumnya dikumpulkan dan diolah akan

\footnotetext{
${ }^{3}$ Nawiyanto \& Eko Crys Endrayadi, Kesultanan Palembang Darussalam; Sejarah dan Warisan Budayanya, Jember: University Press, 2016, hlm. 129.
} 
menghasilkan suatu kesimpulan akhir sehingga menghasilkan penerusan ragam hias makam pada motif songket.

\section{HASIL DAN PEMBAHASAN}

\section{Ragam Hias Motif Songket Pada Kompleks Mkam Kawah Tengkurep}

Pada makam Kawah Tengkurep terdapat beberapa motif songket yang merupakan kerajinan asli daerah Palembang Sumatera Selatan. Pada makam Kawah Tengkurepterdapat 4 motif songket yang ditemukan, yaitu motil pola tumpal (pucuk rebung), motif kandang (meru), motif geometris, dan motif berantai. ${ }^{4}$

\section{a. Motif Pola Tumpal (Pucuk Rebung)}

Motif pola tumpal merupakan motif yang bentuknya seperti Zig-Zag namun lebih tinggi. Motif ini biasa dipakai paling bawah dengan kokoh dan kuat karena motif tersebut berbentuk pondasi. Motif tumpal sering digunakan sebagai hiasan tepi suatu bidang. Tumpal juga sering dikombinasikan dengan motif tumbuhan, terutama untuk isianya. Motif ini terdapat pada nisan kaki dan nisan kepala yang hampir ada diseluruh kompleks makam Kawah Tengkurep. Sedangkan di songket motif ini terdapat di tepian bawah sebagai bentuk hiasan.

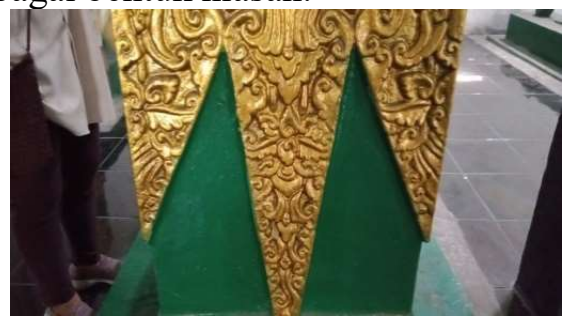

Gambar 1. Motif tumpal pada nisan

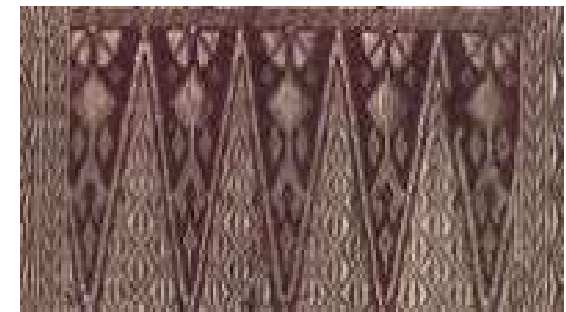

Gambar 2. Motif tumpal pada songket

Persamaan yang terdapat pada motif yang ada pada nisan dan songket yaitu sama-sama berbentuk bambu runcing atau zig-zag, yang didalamnya terdapat motif-motif bunga. Sedangkan perbedaan antara pada motif nisan dan songket yaitu terdapat pada isi dalam tumpal. Pada nisan sendiri isinya terdapat motif bunga-bunga atau sulur-suluran sedangkan yang terdapat di songket isinya terdapat motif-motif geometris.

\section{b. Motif Kandang (Meru)}

Motif Kandang merupakan sebutan nama disongket sedangkan meru sebutan nama di batik karena bentuknya sama. Motif ini terdapat pada jenis songket Thailand. Motif ini merupakan motif yang melambangkan unsur hubungan antara bumi dan tanah, sebagai salah satu dari empat unsur hidup yaitu bumi, api, air, dan angin. ${ }^{5}$ Motif ini terdapat pada bagian sabuk pada nisan kepala dan nisan kaki yang hamper da diseluruh bagian kompleks makam kawah tengkurep.

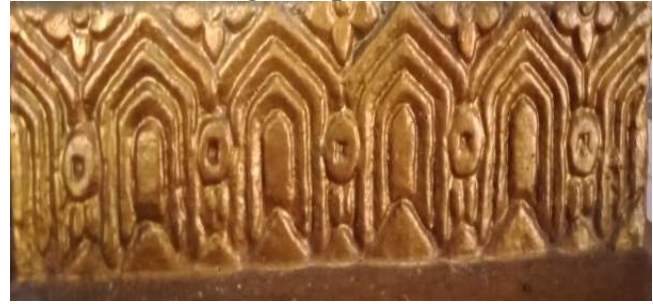

Gambar 3. Motif meru pada nisan

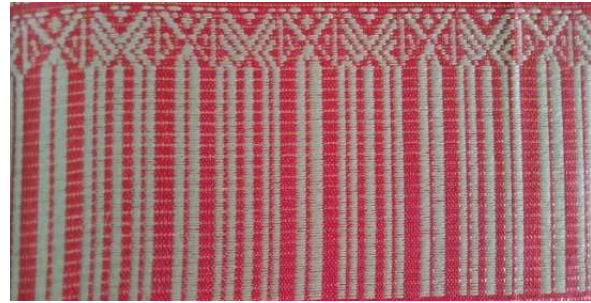

Gambar 4. Motif meru pada songket

\footnotetext{
${ }^{4}$ Observasi Peneliti, 22 Januari 2021.

${ }^{5}$ Susanto. S, Sewan, Seni Kerajinan Batik Indonesia, Jakarta: Balai Penelitian Batik dan Kerajinan , Departemen Perindustrian R. I, 1980, hlm. 261
} 
Persamaan motif meru yang terdapat pada motif pada nisan dan songket yaitu sama-sama memiliki garis-garis yang berbentuk meru. Sedangkan yang membedakan motif pada nisan dan songket yaitu terdapat bulatan-bulatan di tengah motif meru yang ada pada nisan sedangkan pada songket tidak ada.

\section{c. Motif Geometris}

Motif geometris adalah motif yang dianggap tertua diantara motif hias yang lainya, motif geometris berasal dari bentuk objek yang dibuat abstrak dan hanya mengandung makna dan filosofis tersendiri. Hampir di seluruh Nusantara banyak ditemukan ornamen motif geometris merupakan pengembangan warisan budaya yang terdapat pada artefak kebudayaan yang terdapat pada zaman prasejarah yang berasal dari kebudayaan masyarakat Dongson. Motif ini juga terdapat pada kain tenun songket di Sumatera yang sampai saat ini masih berkembang. ${ }^{6}$ Motif geometris ini teletak pada jirat makam pada salah satu makam yang ada di kompleks makam Bahauddin.

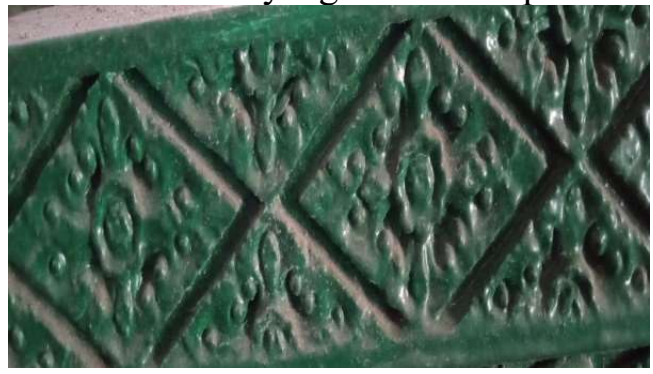

Gambar 5. Motif geometris pada jirat

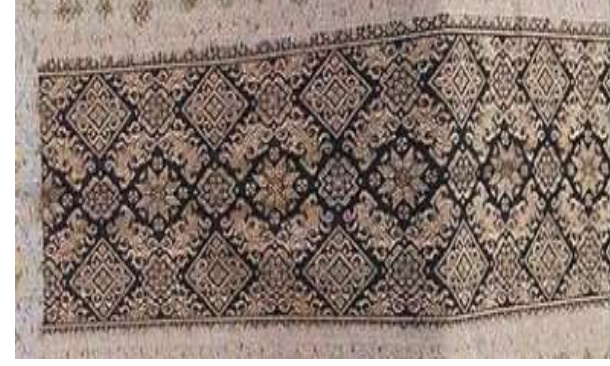

Gambar 6. Motif Geometris pada songket Persamaan motif yang terdapat pada nisan dan songket yaitu sama-sama berbentuk segiempat geometris, sedangkan perbedaan antara motif yang ada pada nisan dan songket yaitu hiasan bunga yang terdapat didalam motif geometris antara keduanya. Motif bunga yang ada pada nisan terdapat empat kelopak bunga sedangkan di songket terdapat delapan kelopak bunga.

\section{d. Motif Berante}

Motif berante atau berantai menunjukkan kembang tengah yang saling berantai atau berkait satu sama lain. Kembang tengah yang menghiasi seolah tak teputus satu sama lain oleh penyatuan antar motif. ${ }^{7}$ Motif berante ini terdapat pada medallion nisan kepala yang ada di salah satu makam kompleks Pangeran Ratu Kamuk.
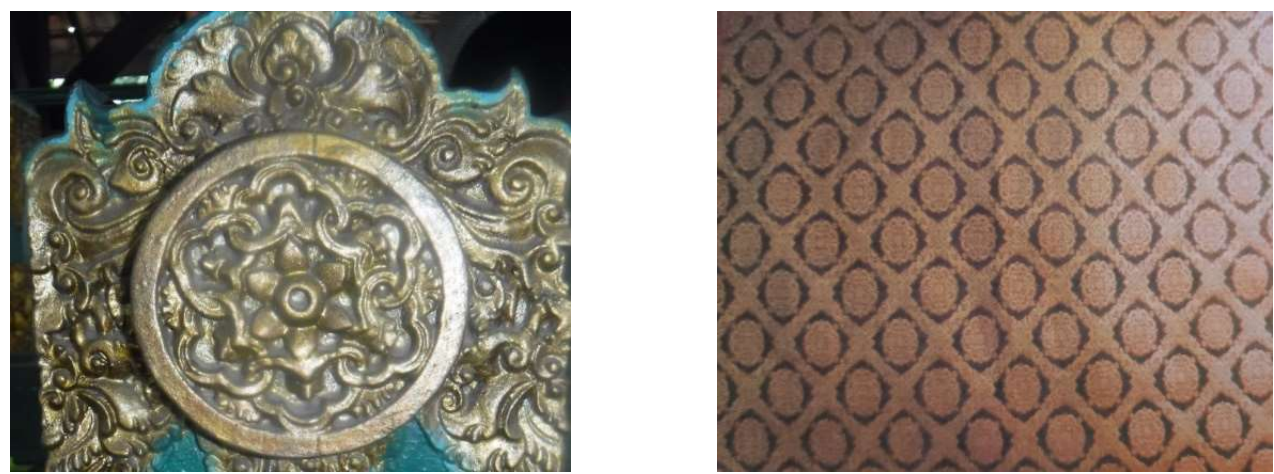

Gambar.7 Motifbunga berante pada nisan Gambar. 8 Motifbunga Berante pada songket

\footnotetext{
${ }^{6}$ Nisfu Laily Hadiyah, Motif Geometris dalam Kreasi Rancangan Busana Muslim, Skripsi: Program Studi Kriya Seni Jurusan Kriya Seni Rupa Institut Seni Indonesia Yogyakarta, 2016, hlm. 3.

7 Yudhy Syarofie, "Songket Palembang; Nilai Filosofi, Jejak Sejarah, dan Tradisi", Palembang: Pemerintahan Provinsi Sumatera Selatan, 2007, hlm. 68.
} 
Persamaan motif yang terdapat pada nisan dan songket yaitu sama sama memiliki kelompak bunga yang saling terkait menyambung antar motif atau berantai, terlihat tidak ada perbedaan motif bunga berantai pada nisan dan songket keduanya sama persis.

\section{Makna Simbolik Motif Songket Pada Kompleks Makam Kawah Tengkurep}

\section{a. Makna Motif Songket Pola Tumpal (Pucuk Rebung)}

Makna filosofis motif Pucuk Rebung, Rebung atau bambu merupakan tumbuhan yang memiliki fungsi penuh dalam kehidupan, dari mulai akar, batang, dan daunnya dapat dimanfaatkan semua serta fungsi tanaman bambu yang dahulu digunakan sebagai pagar kerajaan. Makna filosofis dari motif ini yaitu bagi yang memakainya akan dilindungi dari rintangan dan cobaan serta sebagai lambang kesejahteraan. ${ }^{8}$

Retno Purwanti, Arkeolog Sumsel berpendapat bahwa motif pucuk rebung mempunyai makna bahwa rebung merupakan bagian dari tanaman yang seluruh bagiannya mempunyai manfaat. Tanaman ini juga bisa digunakan sebagai pagar. Biasanya motif pucuk rebung menandakan bahwa seseorang tersebut merupakan keturunan bangsawan. ${ }^{9}$ Dapat disimpulkan bahwa Songket dengan motif pucuk rebung melambangkan sebuah harapan, sebuah doa dan kebaikan. Motif pucuk rebung selalu mengambil tempatnya dalam setiap perayaan adat, Motif tersebut hadir sebagai kepala kain atau tumpal. Mengenakan motif pucuk rebung dimaksudkan agar si pemakai diberkati dengan keberuntungan dan kemudahan dalam setiap langkah hidupnya.

\section{b. Makna Simbolik Motif Songket Kandang (Meru)}

Meru merupakan perlambang dari gunung suci dalam kosmologi Hindu. Meru diyakini sebagai tempat bersemayam para dewa. Dalam tradisi Hindu, digambarkan memiliki ketinggian 84.000 yojana di mana matahari, bulan, planet mengelilinginya. Meru sangat disucikan oleh umat Hindu dan Budha. Konsep Hindu ini kemudian diwujudkan dalam ragam hias songket Palembang. Meru merupakan manifestasi terkait kepercayaan terhadap Tuhan Yang Maha Esa. ${ }^{10}$

Meru sebagai perlambangan sumber segala kehidupan dan sumber kemakmuran. Maka, melalui pemakaian songket motif meru bertujuan memberi sugesti agar pemakainya selalu mendapat perlindungan Tuhan Yang Maha Esa, serta dapat memberikan kebahagiaan baik di dunia dan akhirat. Motif Meru bagi penganut agama Hindu dan Buddha merupakan tuntunan agar manusia berbuat baik karena mendapat pengawasan dan perlindungan dari Tuhan. ${ }^{11}$

\section{c. Makna Simbolik Motif Songket Geometris}

Motif Geometris, yang lebih banyak memanfaatkan unsur-unsur dalam ilmu ukur seperti garis-garis lengkung dan lurus, lingkaran, segitiga, segiempat, bentuk meander, swastika, dan bentuk pilin, bermacam pepatran, patra mesir "L" atau "T" dan lain-lain. ${ }^{12}$

Makna filosofis motif geometris yang terdapat pada makam Kawah Tengkurep Palembang mempunyai arti empat sifat utama yang harus dimiliki seorang pemimpin yaitu: suka membantu, jujur, berhati mulia dan bekerja keras. Motif geometris ini mengambarkan seorang pemimpin yang selalu memikirkan bawahannya dan bersifat rendah hati demi

\footnotetext{
${ }^{8}$ Anita Resianty, Iskandar Syah dan Maskun, Makna Motif Kain Songket Palembang Pada Masyarakat Palembang Di Kecamatan Sako Palembang, Jurnal, tt, h. 13.

${ }^{9}$ Retno Purwanti, wawancara 16 Februari 2021.

${ }^{10}$ Bambang Tri Wardoyo, Konsepsi Hindu pada Ragam Hias Gurdha dan Meru Batik Kraton Yoguakarta, ProdisingSeminar Nasional: Agama, Adat, Seni dan Sejarah di Zaman Milenial, h. 188

${ }^{11}$ Bambang Tri Wardoyo, Konsepsi Hindu pada Ragam Hias Gurdha dan Meru Batik Kraton Yoguakarta, ..... h. 188

12 Iswati, Kajian Estetik dan Makna Simbolik Ornamen di Komplek Makam Sunan Sedang Desa Senda Ngduwur Paciran, Lamongan, Skripsi (Semarang: Fakultas Bahasa dan Seni, 2016), h. 31
} 
kepentingan bersama. Motif ini biasanya ditempatkan dibagian pinggir bawah kain dan disebar dibagian badan kain secara tidak penuh.

Motif ini juga diletakan secara berpencar ke seluruh badan kain yang mempunyai makna simbolis yang arti delapan sifat berdasarkan kepercayaan masyarakat pada masa Kesultanan Palembang, delapan sifat tersebut adalah berbudi pekerti luhur, mementingkan kepentingan kelompok dari pada mementingkan golongan, suka membantu, sopan, jujur, bekerja keras, berhati mulia, dan mempunyai jiwa pemimpin.

\section{d. Makna Simbolik Motif Songket Berantai}

Motif songket berantai merupakan jenis songket yang menunjukkan ragam hias tengahnya saling berantai atau atau berkait satu sama lainnya. ${ }^{13}$ Makna filosofis motif berantai melambangkan kesucian dan sopan santun. Motif ini juga menunjukkan relasi yang terjalin antara masyarakat satu dengan yang lainnya bukan sekedar ada hubungan saudara saja, tetapi sudah menjadi fitrah manusia sebagai makluk sosial yang selalu menjalin hubungan dan komunikasi dengan manusia atau kelompok lainnya. Antara individu masing-masing memiliki kepentingan sendiri sebagai wujud eksitensi diri, tetapi kepentingan individu tentunya harus melihat kepentingan bersama (kolektif) untuk saling menghargai di antara kepentingan-kepentingan tersebut. ${ }^{14}$

Motif berantai ini biasanya diperuntukkan untuk wanita bangsawan. Seperti yang dikemukakan oleh R.H.M Akib seperti dikutip oleh Suwarti Kartiwa, bahwa kain songket erat hubungannya dengan wanita dan didalamnya mencerminkan wanita. Hal ini tampak dari dengan banyaknya motif bunga yang diterapkan dalam desain kain songket dan kalau kemudian dalam adat terdapat pakaian yang dipakai oleh laki-laki, maka itu adalah perkembangannya yang kemudian karena pada zaman dahulu kain songket ditenun oleh para gadis sambil menunggu datangnya lamaran dari pihak laki-laki. ${ }^{15}$

Seperti halnya daerah-daerah lain, masyarakat Palembang memiliki keharusan untuk memakai kain songket dalam setiap upacara yang dilakukan (pakaian adat). Kain songket digunakan pada setiap upacara keagamaan, perkawinan ataupun upacara adat lainnya dan tidak untuk dipakai sehari-hari. Ini semua menandakan kalau kain songket tidak bisa dipakai sembarangan, karena di dalamnya mengandung makna-makna tertentu. Makna ini merupakan perlambang dari sipemakai. Sebagai contoh, pemakaian kain songket untuk upacara perkawinan berbeda dengan yang digunakan untuk upacara keagamaan dan upacara adat lainnya. Perbedaan itu dapat dilihat pada warna merah cabe yang biasa dipakai oleh pengantin sedangkan untuk upacara adat lainnya bebas memilih motif dan warna. Dahulu pemakaian kain songket dibedakan antara untuk keluarga kerajaan, pegawai kerajaan, golongan bangsawan dan rakyat biasa. Perbedaan pemakaian kain songket penting karena dalam kain songket mempunyai motif-motif tersendiri yang menggambarkan kebesaran dan keagungan seseorang (pemakai).

\section{E. KESIMPULAN}

Kompleks makam kawah tegkurep yang di berada di 3 Ilir Palembang memiliki empat cukungkup yaitu cungkup Sultan Mahmud Badaruddin 1, cungkup Sultan Ahmad Najamuddin, cungkup Sultan Muhammad Bahauddin, dan cungkup Pangeran Ratu Kamuk. Ragam hias yang terdapat pada situs makam Kawah Tengkurep terdiri dari ragam hias motif flora, fauna, kaligrafi arab,

13 Endang Tri Wahyuni, Makna Simbolis Motif Tenun Songket Aesan Gede dalam Prosesi Pernikahan Adat Palembang Sumatera Selatan, Tesis (Surakarta, Program Pascasarjana ISI, 2015), h. 55

${ }^{14}$ Romas Tahrir, Tjetjep Rohendi Rohidi, Sri Iswidayati, Makna Simbolis dan Fungsi Tenun Songket Bermotif Naga pada Masyarakat Melayu di Palembang Sumatera Selatan, Catharsis: Journal of Arts Education, 6 (1) 9-18 (2017), h. 16

${ }^{15}$ Suwarti, Kartiwa, Songket Indonesia, (Jakarta: Djambatan, 1996), h. 34. 
meru, sinar surya majapahit dan suluran-suluran. Ragam hias ini terdapat pada nisan kepala, nisan kaki dan juga jirat makam.

Berdasarkan penelitian terdapat 4 motif songket yang ditemukan di Kompleks Mkam Kawah Tengkurep yaitu motif tumpal atau pucuk rebung terletak pada nisan kepala dan nisan kaki hampir di seluruh kompleks makam Kawah Tengkurep, motif meru terletak pada sabuk nisan kaki dan nisan kepala hampir ada diseluruh kompleks makam Kawah Tengkurep, motif geometris terletak pada jirat makam di kompleks makam Bahauddin, dan motif berante terletak pada nisan kepala di kompleks makam Pangeran Ratu Kamuk. Motif-motif ini memiliki persamaan dan sedikit perbedaan pada setiap bentuk ragam hias yang ditemukan.

Beberapa makna simbolik motif songket yang ada pada makam Kawah Tengkurep yaitu 1) motif pucuk rebung melambangkan sebuah harapan, sebuah doa dan kebaikan, 2) motif kandang (meru) melambangkan tuntunan agar manusia berbuat baik karena mendapat pengawasan dan perlindungan dari Tuhan, 3) motif geometris mempunyai arti empat sifat utama yang harus dimiliki seorang pemimpin yaitu: suka membantu, jujur, berhati mulia dan bekerja keras, dan 4) motif berantai melambangkan kesucian dan sopan santun, motif ini juga menunjukkan relasi yang terjalin antara masyarakat satu dengan yang lainnya bukan sekedar ada hubungan saudara saja, tetapi sudah menjadi fitrah manusia sebagai makluk sosial yang selalu menjalin hubungan dan komunikasi dengan manusia atau kelompok lainnya.

\section{DAFTAR PUSTAKA}

Anita Resianty, Iskandar Syah dan Maskun, Makna Motif Kain Songket Palembang Pada Masyarakat Palembang Di Kecamatan Sako Palembang, Jurnal.

Bambang Tri Wardoyo, Konsepsi Hindu pada Ragam Hias Gurdha dan Meru Batik Kraton Yogyakarta, Prodising-Seminar Nasional: Agama, Adat, Seni dan Sejarah di Zaman Milenial.

Bambang Tri Wardoyo, Konsepsi Hindu pada Ragam Hias Gurdha dan Meru Batik Kraton Yogyakarta.

Dekdikbud, Esiklopedia Nasional Indonesia Jilid VIII, Jakarta: PT Cipta Abadi Pustaka, 1992.

Endang Tri Wahyuni, Makna Simbolis Motif Tenun Songket Aesan Gede dalam Prosesi Pernikahan Adat Palembang Sumatera Selatan, Tesis, Surakarta, Program Pascasarjana ISI, 2015.

Iswati, Kajian Estetik dan Makna Simbolik Ornamen di Komplek Makam Sunan Sedang Desa Senda Ngduwur Paciran, Lamongan, Skripsi, Semarang: Fakultas Bahasa dan Seni, 2016.

Nawiyanto \& Eko Crys Endrayadi, Kesultanan Palembang Darussalam; Sejarah dan Warisan Budayanya, Jember: University Press, 2016.

Nisfu Laily Hadiyah, Motif Geometris dalam Kreasi Rancangan Busana Muslim, Skripsi: Program Studi Kriya Seni Jurusan Kriya Seni Rupa Institut Seni Indonesia Yogyakarta, 2016.

Retno Purwanti dan Sodang M. Siregar, "Sejarah Songket Berdasarkan Data Arkeologi", Siddhayatr, 2016.

Romas Tahrir, Tjetjep Rohendi Rohidi, Sri Iswidayati, Makna Simbolis dan Fungsi Tenun Songket Bermotif Naga pada Masyarakat Melayu di Palembang Sumatera Selatan, Catharsis: Journal of Arts Education, 6 (1) 9-18, 2017.

Susanto. S, Sewan, Seni Kerajinan Batik Indonesia, Jakarta: Balai Penelitian Batik dan Kerajinan, Departemen Perindustrian R.I, 1980.

Suwarti, Kartiwa, Songket Indonesia, Jakarta: Djambatan, 1996.

Yudhy Syarofie, "Songket Palembang; Nilai Filosofi, Jejak Sejarah, dan Tradisi", Palembang: Pemerintahan Provinsi Sumatera Selatan, 2007. 